\section{SCIENTIFIC SERIALS}

American Fournal of Science and Arls, April 1876.--Prof. Wright, of Yale College, examined last year the gases obtained at moderate temperature from a stony meteorite of Iowa County; their chief constituent was carbon dioxide. He has further examined several other meteorites of both classes (stony and iron, five of each), and the results, here communicated, confirm his former conclusions. Not only do the stony meteorites give off much more gas at low temperatures than the iron, but the composition is quite distinct. In no case of the latter was the amount of carbon dioxide more than 20 per cent. at $500^{\circ}$, nor than Is per cent. from the whole quantity evolved, and the volume of carbonic oxide was, in every case but one, considerably larger. In the chondrites, on the other hand, the percentage of carbonic oxide is very small, while the carbon dioxide is (with one slight exception) more than half of the total quantity of gas obtained up to red heat. At a temperature of about $350^{\circ}$ it constitutes from 80 to 90 per cent. of the gaseous products, in all cases, while at the heat of $100^{\circ}$ it forms somewhat more than 95 per cent. in the two cases examined in this respect. The hydrogen, on the other hand, progressively increases in quantity with rise in the temperature of evolution, and in the last portions given off at a red heat is generally the most important constituent. The evolution of those large volumes of carbon dioxide may be taken as characteristic of the stony meteorites, and its relation to the theory of comets and their trains is certainly of great significance.-Prof. Norton gives a succinct account of researches made with a view to determine the laws of the set of materials resulting from a transverse strain under various circumstances. He studied (I) sets from momentary strains, (2) sets from prolonged strains, and (3) duration of set, and variation of set with interval of time elapsed after the withdrawal of the stress. Some of the results are rather at variance, apparently, with the conception of the ultimate molecule, as made up of a limited number of precisely similar atoms endued with unvarying forces of attraction at certain distances and repulsion at other distances.-According to Prof. Le Conte, mountain ranges are formed wholly by a yielding of the crust along cer. tain lines of horizontal pressure; not, however, by bending of the crust into a convex arch filled and sustained by a liquid beneath, but by a crushing or mashing together horizontally of the whole crust with the formation of close folds and a thickening or swelling upward of the squeezed mass. In an interesting paper he adduces evidence of this from the coast range of California, which is destitute of granite axes, and has been little changed by metamorphism or overlaid by igneous ejections.--Prof. Newcomb criticises somewhat unfavourably the physical theories of climate maintained in Croll's recent work on Climate and Time in their Geological Relations. -- Prof. Mallet studies the constitutional formulie of urea, uric acid, and their derivatives, and in an appendix Prof. Marsh describes the principal characters of the Brontotheridæ, with aid of some excellent plates.

Mind, April.--In this number Mr. G. H. Lewes draws attenfion to the alsence of strictly defined technical terms in psychology, and "the deplorable and inevitable ambiguity" which in consequence clouds the discussion of psychological questions. After referring to various senses in which the words sensation, sensibility, consciousness are used, he puts the question: "are all changes in the sensitive organism to be included under the term consciousness, or only some changes?" We believe some psychologists would answer : no changes in an organism ought to be called consciousness.--Prof. W. Wundt of Leipsic contributes a solid paper on "Central Innervation and Conscious. ness." He accepts physical automatism as flowing from the doctrine of the conservation of energy. "If this principle lays claim to a universal validity, we cannot withdraw from it those movements which we are conscious of only as psychologically caused." What he means by psychological causation is not very clear.-M. Sidgwick's "Methods of Ethics" is ably reviewed by Prof. Bain, who while speaking of the work in terms of highest praise, finds, nevertheless, that justice has scarcely been done to utilitarian ethics, and when Mr. Sidgwick, finding no complete answer to the immoral paradox, "My performance of social duty is good not for me but for others," concludes that our cosmos of duty is in reality a chaos, Prof. Bain tbinks that we have here "a sad ending to a great work;" and he proceeds to give a. solution of his own, which some may consider little more than a restatement of the difficulty, The next paper is a criticism of Mr. Sidgwick's chapter on "Intuitionalism," by Mr. H. Calder- wood, who endeavours to show that Mr. Sidgwick has "largely failed in the attempt to give a clear and fair representation of intuitionalism." The editor, Prof Croom Robertson, reviews Mr. Jevons's "Formal Logic." He praises the ability, ingenuity, and even success with which Mr. Jevons has laboured to construct a brand-new system, but is compelled at the same time to maintain the superiority of the methods of the traditional logic. - Mr. Shadworth H. Hodgson continues the work of distinguishing between philosophy and science. His present paper, "As Regards Psychology," is delightfully hard reading. - "Philosophy at Cambridge," is treated by Mr. H. Sidgwick.--A short kindly biography of James Hinton is written by Mr. J. F. Payne.-Critical notices, reports, correspondence, \&c., make up the number.

Memorie della Societd Spettroscopisti Italiani, November, 1875 . - Prof. Bredichin writes an article on the spectra of certain nebulx relating how he has adopted the plan of comparing the lines of the spectrum of the nebula with the Fraunhoffer lines of the sun. The spectrum of a Geisler tube of hydrogen is used as an intermediate means of comparison. The mean positions of the lines are $5^{00} 3^{\circ} 9,5957^{\circ} 9,4^{8} 59^{\circ} 2$ respectively. The first two lines agree very closely with the iron lines $5005^{\circ} \mathrm{O}$ and 5956.5 . -A comparison of the solar diameters as nbtained by the spectroscopic and transit methods by Secchi, Tacchini, and Kayet. The mean of the spectroscopic observations gave a diameter I" 8 less than the latter method.

Decermber 1875. - Father Secchi contributes a note on his researches on the distribution of heat on the solar disc.-Prof, Ricco writes on the perception and persistence of the sensa'ion of colours. He throws a spectrum on a screen by reflection from an oscillating mirror, so that the spectrum is moved in a dire:tion at right angles to its length backwards and forwards, and the shape of the apparent envelope of the coloured band shows that yellow is the most rapidly perceived colour, and the others decrease towards the red and blue. - Prof. Oudemanns writes on a method of heliometric measurement on the occasion of the transit of Venuts. - Prof. Fergola writes on the dimensions of the earth, and researches on the position of the axis of figure with respect to the axis of rotation.

\section{SDCIETIES AND ACADEMIES \\ LONDON}

Royal Society, May 18.- "Picrorocellin," by John Sten. house, F.R.S., and Charles Edward Groves.

"On the Polarisation of Light by Crystals of Iodine," by Sir John Conroy, Bart., M.A. Communicated by A. G. Vernon Harcourt, Lee's Reader in Chemistry in the University of Oxford.

"Absorption-Spectra of Iodine," by Sir John Conroy, Bart., M. A. Communicated by A. G. Vernon Harcourt, Lee's Reader in Chemistry, University of Oxford.

Linnean Society, May 4.-Mr. G. Bentham, vice-president, in the chair. -Mr. G. Dawson Rowley and Mr. G. H. Parkes were elected Fellows of the Society.--Two foreign savans were chosen to fill the vacancies caused by death among the honorary members. - Mr. H. Trimen called attention to the photograph of a remarkable example of fasciated inflorescence occurring in Fourcroya cubensis, Haw. The specimen, coming unter the ob. servation of A. Ernst, of Caraccas, is recorded as $6 \frac{1}{2}$ feet high and 4 feet wide. $-O n$ behalf of Dr. Anderson there were shown specimens demonstrating the extraordinary diminutive eye of the Indian River Whale (Platanista gangetica), which animal to all intents and purposes must be well nigh blind; and likewise spe. cimens of grasses (Ischamum rugosum and Faspalum scrobuculatum) obtained from the stomach of the same creature, probably residual digesta of fish eaten by it.-Dr. Cobbold read a paper on Trematode parasites from gangetic dolphins. Three species were lucidly described, viz., Distoma lancea, D. campula, and $D$. Andersoni. The first of these was procured from the shortsnouted Dolphin (Orcella brezirostris), a form more frequently captured in the Indian river estuaries. The last mentioned is entirely new to science. It and that immediately preceding (formerly desiguated Campula oblonga) were both obtained by Dr. J. Anderson from different specimens of the fluviatile Cetacean (Flatanista). The special interest attached to the parasites in question may be thus summarised. 1 . The circumstance of being obtained from Cetacean hosts not previously known to be 